\title{
DNA Status on Thawed Semen from Fighting Bull: A Comparison Between the SCD and the SCSA Tests
}

\author{
F Martínez-Pastor, M del Rocío Fernández-Santos, ÁE Domínguez-Rebolledo, MC Esteso, JJ Garde; Biology of Reproduction \\ Group \\ National Wildlife Research Institute (IREC) (UCLM-CSIC-JCCM) and Institute of Regional Development (IDR), Section of Cynegetics and \\ Cattle Resources, University of Castilla-La Mancha, Albacete, Spain
}

\section{Contents}

The assessment of sperm chromatin status is compulsory in a complete spermiogram. Here we applied the sperm chromatin structure assay (SCSA) and the sperm chromatin dispersion (SCD) test to assess the chromatin status of three fighting bulls. Cryopreserved semen (two straws/bull) were analysed by duplicate after thawing and after $6 \mathrm{~h}$ at $37^{\circ} \mathrm{C}$ with and without oxidative stress $\left(1 \mathrm{mM} \mathrm{Fe}^{24}\right)$. Results (SCD: percentage of spermatozoa with halo; SCSA: SD-DFI, \%DFI and HDS) were analysed for differences between bulls and treatments, sensitivity and specificity (receiver operating characteristic curves) and repeatability (repeatability coefficients as 2SD of duplicate differences). $\%$ DFI for the three bulls was below $2 \%$ at $0 \mathrm{~h}$, indicating no risk for fertility according to previous reports. It increased slightly for two of the bulls after $\mathrm{Fe}^{24}$ treatment $(\% \mathrm{DFI}<5 \%)$ and more pronouncedly for the other bull $(\mathrm{C}, \% \mathrm{DFI} \sim 10 \%)$, which merits further investigation. SCD rendered higher percentage of halos for bull C, but could not discriminate between samples with and without oxidizing treatment (AUC: 0.52). SCSA (\%DFI) showed a high discriminating ability between treatments (AUC: 0.96). The repeatability coefficient was also higher for SCD (5.9) than for $\%$ DFI (1.8), indicating lower repeatability for SCD. Overall, \%DFI might be the most useful parameter for assessing sperm chromatin on fighting bull. SCD might yield different information than SCSA, hence further research is warranted.

\section{Introduction}

2 Among the huge choice of tests for semen analysis developed in the last years, DNA assessment has gained increasing attention. Indeed, DNA defects are recognized as one factor responsible for uncompensable defects, meaning that the fertility of the given sample cannot be improved by increasing the number of spermatozoa for insemination (Evenson 1999; Saacke et al. 2000). These defects also reduce the success rates

3 of IVF or ICSI. Taking into account the great number of factors that can impair the DNA integrity of the spermatozoa, either during spermatogenesis (male genetics, health, environment) or afterwards (infections, oxidative damage, manipulation), an effective and affordable test to assess the sperm DNA integrity should be considered as a requirement for a complete spermiogram (Agarwal and Allamaneni 2005). The evaluation of sperm DNA has been based on many strategies: direct study of DNA breaks (TUNEL, DBDFISH, in situ nick translation, Comet assay), chromatin affinity to staining (toluidine blue, chromomycin A3), in situ acid-induced DNA denaturation [sperm chromatin structure assay (SCSA)], DNA dispersion after using low $\mathrm{pH}$ and reducing agents [sperm chromatin dispersion (SCD) test] and many others (Agarwal and Allamaneni 2005; Erenpreiss et al. 2006). There is ample literature on these techniques, with many interpretations of the results and, very often, disagreement on its effectivity and clinical value (Agarwal and Said 2003; Agarwal and Allamaneni 2005). In this article we present a study in which two techniques for assessing sperm DNA integrity on frozen/thawed bull spermatozoa were tested. The golden standard in this study was the $\mathrm{SCSA}^{\mathrm{TM}}$, currently the only technique that has been extensively tested and whose clinical value seems to be sufficiently contrasted (Erenpreiss et al. 2006). The other technique tested was the SCD test, a recently developed technique for assessing sperm chromatin, which is relatively simple and inexpensive. SCSA ${ }^{\mathrm{TM}}$ is based on the in situ acid-induced DNA denaturation, followed by staining the sample with the metachromatic stain acridine orange (Evenson et al. 2002). This stain intercalates in the DNA, giving green fluorescence if the intercalating site is double-strand DNA (native), and red fluorescence if the site is single-strand DNA (denatured). The cells are run through a flow cytometer, and the fluorescence values of each cell are used for obtaining a DNA fragmentation index (DFI), which is the relation between red and total fluorescence. DNA regions with breaks are highly susceptible to denature during acid treatment, and thus cells with damaged DNA have a higher DFI. Spermatozoa are then classified according to whether their DFI is low, moderate or high (typically, DFI is considered moderate when it is between 20,25 and 75 , or high if it is above 75). The percentage of spermatozoa with moderate or high DFI (also called DFI) is then used to determine the DNA integrity of the sample. SCSA ${ }^{\mathrm{TM}}$ has been extensively used for human semen and is considered as reliable and repeatable (Evenson et al. 2002). Indeed, there are prognostic cut-off values for the DFI of a human semen sample. Thus, when DFI is higher than $30 \%$ it is considered that the fertility of the sample will be greatly compromised (Bungum et al. 2007). The technique has been successfully tested in other mammals, such as boar (De Ambrogi et al. 2006; Hernandez et al. 2006), ram (Martinez-Pastor et al. 2004; Garcia-Macias et al. 2006b,c; Kasimanickam et al. 2006b), stallion (Lo et al. 2002; Dias et al. 2006), dog (Nunez-Martinez et al. 2005; Garcia-Macias et al. 2006c) and several wild species (Garcia-Macias et al. 2006b,c; Fernandez-Santos et al. 2007). Domestic

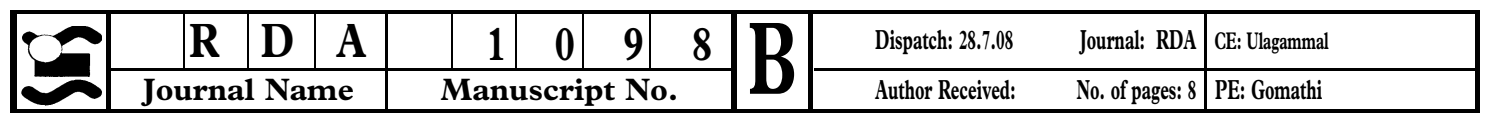


cattle has received much more attention than any other species, apart from humans. In fact, it has been known for 20 years that bull fertility is related to SCSA results (Ballachey et al. 1987). Subsequent studies have confirmed the relationship of SCSA not only with field fertility but also with other physiological and morphological characteristics of bull spermatozoa (Evenson 1999; Bochenek et al. 2001; Ostermeier et al. 2001; Januskauskas et al. 2003; Garcia-Macias et al. 2006a; Kasimanickam et al. 2006a; Waterhouse et al. 2006) and it has been suggested that values of DFI $\geq 20 \%$ might announce lower fertility (Evenson 1999). Nevertheless, clear DFI cut-off values for fertility prognosis have not been defined, neither for cattle nor for other non-human species, although there are some efforts in this sense (Love 2005). In contrast, the SCD has been in use for less than 5 years (Fernandez et al. 2003). This technique is based on the inclusion of spermatozoa in a gel matrix, applying a high-salt low-pH treatment (including reducing agents to break disulphydryl bonds in the chromatin). After this treatment, the sample is analysed by brightfield or fluorescence microscopy, obtaining the percentage of sperm heads with a halo. Depending on the commercial kit used (presence or not of a denaturation treatment in order to optimize the test for different species, according to the authors), the halos indicate either good or bad condition of the sperm DNA (Fernandez et al. 2003; Perez-Llano et al. 2006). The SCD is relatively easy to perform and does not require expensive equipment. However, it is recommended to count at least 500 spermatozoa, which can be very time-consuming if analysing many samples. The technique has been used to evaluate semen samples from humans, boars and bulls (Fernandez et al. 2005a; Enciso et al. 2006; Garcia-Macias et al. 2006a; PerezLlano et al. 2006; Muriel et al. 2007). However, due to the short time this technique has been on use, it is not sure whether it has a relationship to fertility (Muriel et al. 2006b), although some studies indicate that a relationship indeed may exist (Muriel et al. 2006a), and that it may have a performance comparable to SCSA or TUNEL (Chohan et al. 2006). Nevertheless, this test has yet to be fully validated for its clinical use. Its usefulness is still subject to controversy, especially due to its high variability, which may hamper its diagnostic and prognostic use (Evenson and Wixon 2005a; Schlegel and Paduch 2005). In this study we show the results of the first chromatin assessment of fighting bull spermatozoa. This breed is highly valued in Spain and 4 many South American countries, being sensible to establish germplasm banks for the conservation of its genetic resources (Blackburn 2004). However, these animals are reared following traditional and extensive

5 procedures, and males are frequently killed before testing fertility or seminal characteristics. Thus, the use of seminal doses from males killed in bullfighting (epididymal sperm) or kept as breeders (electro ejaculation) would have to rely on the assessment of the cryopreserved semen prior to its use. In this context, the application of sensitive analysis for assessing sperm DNA integrity would be especially interesting, in order to discard samples with bad fertility prognosis. The aim of the present study was to determine the potential of
SCSA and SCD for evaluating cryopreserved fighting bull doses. To achieve this objective, we aimed at detecting between-bull differences. As these differences are usually small and the number of different doses from this breed is scarce, we submitted the samples to oxidative stress, thus inducing alterations on the DNA .

6Having set up this positive treatment, we tested the repeatability and sensitivity (ability to correctly discriminate samples treated with the oxidant from 100 7 those untreated) of each test.

\section{Materials and Methods}

\section{Experimental design}

All chemicals were at least of Reagent grade, and acquired from Sigma (Madrid, Spain). Sperm-BosHalomax $^{\circledR}$ (for fluorescence microscopy) was acquired from ChromaCell SL (Madrid, Spain). For the experiment, we collected and froze samples from three fighting bulls (from now on termed bulls A, B and C) from the germplasm bank we maintain in our laboratory for this breed. We thawed two straws from each bull, which were processed separately. Semen was diluted in phosphate-buffered saline (PBS) and split between a Control and an Oxidant treatment. For the Oxidant treatment, we added $\mathrm{FeSO}_{4}(100 \mu \mathrm{M})$ and sodium ascorbate $(1 \mathrm{~mm})$. $\mathrm{Fe}^{2+}$ oxidizes to $\mathrm{Fe}^{3+}$, which is recycled by the ascorbate, producing the highly reactive hydroxyl radical (HO). Samples were incubated for $6 \mathrm{~h}$ in order to induce oxidative stress. It has been previously demonstrated that this kind of treatment causes sperm DNA damage, including strand breaks (Chen et al. 1997; Lloyd and Phillips 1999). The samples were kept in a water bath at $37^{\circ} \mathrm{C}$. We analysed DNA integrity at 0 and $6 \mathrm{~h}$ by using SCSA (Evenson and Wixon 2005b) and SCD (Halo$\max ^{(\circledR)}$.

\section{Animals, electroejaculation and semen cryopreservation}

Animal manipulations were performed in accordance with the Spanish Animal Protection Regulation, RD223/1988, which conforms to European Union Regulation 86/609. The males were selected fighting bulls used for breeding. They were kept isolated in individual enclosures and were healthy and reproductively mature at the time of the collection of the study. Previous to electroejaculation, bulls were anaesthetized using xylazine $(0.1 \mathrm{mg} / \mathrm{kg}$ Rompun $2 \%$; Bayer, Germany) and Mepivacaine $(0.16 \mathrm{mg} / \mathrm{kg}$ Mepivacaine $\mathrm{HCl} \mathrm{2 \%}$; Braun, Germany) (Álvarez et al. 2006). Semen was collected by electroejaculation using a sine-wave stimulator (P.T. Electronics, Boring, OR, USA). The stimulator was capable of monitoring voltage and amperage and used an AC current of $220 \mathrm{~V} / 60 \mathrm{~Hz}$, with a transformer producing a maximum of $55 \mathrm{~V}$ and $1.5 \mathrm{~A}$. The stimulating voltage was delivered using rectal probes with three longitudinal surface-mounted electrodes. Probe diameter, probe length and electrode length were 4.5, 37.5 and 126 $8.5 \mathrm{~cm}$ respectively. The probe was lubricated and gently inserted into the rectum, and orientated so that the electrodes were positioned ventrally. The penis was 
prolapsed beyond the prepuce and semen collected SCSA

using a 30-ml sterile plastic container, which was kept warm by covering it with the hand. The electroejaculation regime used was based on that employed previously for ungulates (Howard et al. 1981; Roth et al. 1998) with various modifications. It consisted of consecutive series of 5-s pulses of similar voltage, each separated by a 5-s break. Each series consisted of a total of four pulses (Garde et al. 2003). Semen was placed in a water bath at $30^{\circ} \mathrm{C}$ until processed. For freezing, we supplemented Biladyl (Fraction A and B; IMV, L'Aigle, France) with $20 \%$ egg yolk.

Semen was diluted to $100 \times 10^{6}$ cells $/ \mathrm{ml}$ in glass tubes with Biladyl Fraction A at $30^{\circ} \mathrm{C}$. The tubes were placed in beakers with $100 \mathrm{ml}$ of water at the same temperature, and the beakers were placed in a walk-in fridge at $5^{\circ} \mathrm{C}$ (slow cooling). When water temperature reached $5^{\circ} \mathrm{C}$, Biladyl Fraction B (12\% glycerol) was added $1: 1$ (final concentration of glycerol: $6 \%$ ). The samples were 1 left to equilibrate for $4 \mathrm{~h}$ and then packed in $0.5 \mathrm{ml}$ straws $\left(50 \times 10^{6}\right.$ cells $/$ straw $)$. Freezing was carried out in liquid nitrogen vapours $(4.5 \mathrm{~cm}$ above liquid nitrogen level; $-20^{\circ} \mathrm{C}$ ). Straws were stored in liquid nitrogen for a year.

\section{Thawing and sample processing}

Thawing was carried out by dropping the straws into a water bath at $37^{\circ} \mathrm{C}$ for $30 \mathrm{~s}$. Semen was diluted in PBS $\left(10^{7} \mathrm{spz} . / \mathrm{ml}\right)$, from which we took $1 \mathrm{ml}$ as a Control and $1 \mathrm{ml}$ as the Oxidant treatment. To the Oxidant tube, we added $10 \mu \mathrm{l}$ of $10 \mathrm{~mm} \mathrm{FeSO}_{4}$ and $100 \mathrm{~mm}$ sodium ascorbate in water (final: $100 \mu \mathrm{M} \mathrm{Fe} \mathrm{Fe}^{2+}$ and $1 \mathrm{~mm}$ ascorbate). Both tubes were placed in a water bath at $37^{\circ} \mathrm{C}$.

\section{Sperm chromatin dispersion test}

For carrying out the SCD test, samples were treated with the commercial kit Sperm-Bos-Halomax ${ }^{\circledR}$ following the protocol included with the kit. Twenty-five microlitres of sperm sample was added to a vial containing $50 \mu \mathrm{l}$ of liquid low-melting agarose at $37^{\circ} \mathrm{C}$. Then, $25 \mu \mathrm{l}$ of the solution $(\sim 3 \times 106 \mathrm{spz} . / \mathrm{ml})$ was placed on an agarose pre-treated slide provided with the kit and cooled at $4^{\circ} \mathrm{C}$. The drop was covered with a coverslip $(22 \times 22 \mathrm{~mm})$ and the slide was placed at $4^{\circ} \mathrm{C}$ for $5 \mathrm{~min}$. The coverslip was then carefully removed and the slide was immediately put into lysing solution at ambient temperature. After $4 \mathrm{~min}$, the slide was washed for $5 \mathrm{~min}$ in distilled water and sequentially dehydrated in ethanol $(70 \%, 90 \%, 100 \%)$. After dehydration, slides were examined for a few hours by fluorescence microscopy, staining for $10 \mathrm{~min}$ with $5 \mu \mathrm{l}$ of staining solution (provided with the kit) mixed with $10 \mu \mathrm{l}$ of $1 \mathrm{~mm}$ of 1,4diazabicyclo[2,2,2]octane (DABCO) in $30 \%$ glycerol in water (antifade solution). Fluorescence was observed using a 510-560 nm excitation filter and a $590 \mathrm{~nm}$ emission filter, at $\times 400$ magnification. Spermatozoa were classified as having a halo (damaged DNA) or not, recording the percentage of spermatozoa with halo. The same observer, trained on the technique, performed all analysis.
9The SCSA technique (Evenson et al. 2002) is based in the metachromatic stain acridine orange, which fluoresces green when combined with double-stranded DNA, and red when combined with single-stranded DNA (denatured). Spermatozoa were diluted in TNE buffer $(0.15 \mathrm{~m} \mathrm{NaCl}, 0.01 \mathrm{~m}$ Tris $\mathrm{HCl}, 1 \mathrm{~mm}$ EDTA; $\mathrm{pH}$ $7.4)$ to $2 \times 10^{6} \mathrm{ml}^{-1}$. Samples were flash frozen in LN2 and stored at $-80^{\circ} \mathrm{C}$ until analysis. For the analysis, the samples were thawed on crushed ice and $200 \mu \mathrm{l}$ was put on a cytometry tube. We then added $400 \mu \mathrm{l}$ of an aciddetergent solution $(0.08 \mathrm{M} \mathrm{HCl}, 0.15 \mathrm{M} \mathrm{NaCl}, 0.1 \%$ Triton X-100, pH 1.2). Exactly $30 \mathrm{~s}$ after adding the acid-detergent solution, we added $1.2 \mathrm{ml}$ of staining solution $(6 \mu \mathrm{g} / \mathrm{ml}$ of acridine orange in a buffer containing $37 \mathrm{mM}$ citric acid, $126 \mathrm{~mm} \quad \mathrm{Na}_{2} \mathrm{HPO}_{4}$, $1.1 \mathrm{~mm}$ disodium EDTA and $150 \mathrm{~mm} \mathrm{NaCl}$; $\mathrm{pH} 6$ ). We left the sample staining for $3 \mathrm{~min}$, and then we ran it through a Becton Dickinson LSR-1 flow cytometer. We excited the acridine orange using an argon laser providing $488 \mathrm{~nm}$ light. The red fluorescence was detected using a long-pass (670LP) filter (FL-3) and the green one using a band-pass $(530 / 28 \mathrm{BP})$ filter (FL1). Both photodetectors were adjusted using linear scales. Sample acquisition was carried out with the

11CellQuestv.3 software. Flow cytometry data (FCS files) were processed and saved as tabbed text using WinMDI v.2.8 (The Scripps Research Institute, La Jolla, CA, USA). We calculated the DFI for each spermatozoa as the ratio of red fluorescence with respect to total fluorescence (red + green), expressed as a percentage. The processing of DFI data was performed using the $\mathrm{R}$ statistical environment ( $\mathrm{R}$ Development Core Team, 2007). From the DFI values, we obtained the standard deviation of DFI (SD-DFI). The percentage of spermatozoa with high fragmentation index (\%DFI) was calculated as the percentage events with DFI $>25 \%$ (Fig. 1). We also obtained the high DNA stainability index (HDS) as the percentage of spermatozoa with green fluorescence intensity above channel 600 (0-1023 channels).

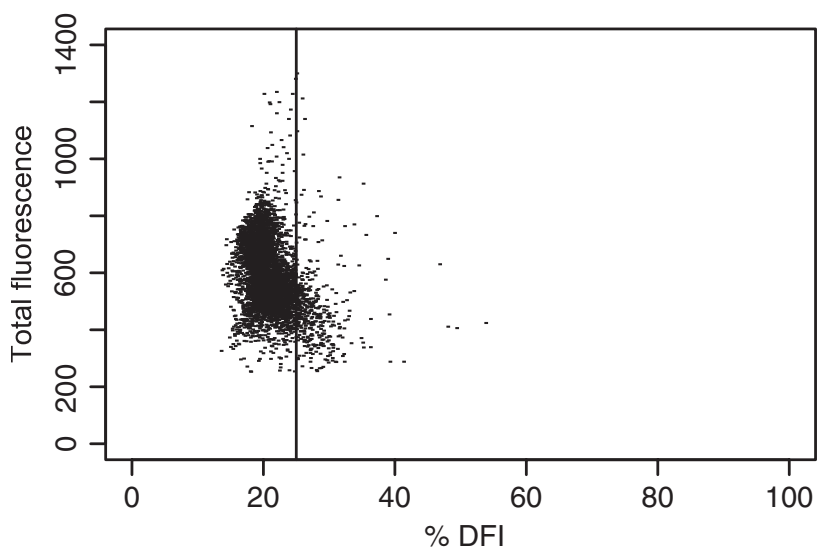

Fig. 1. Example of dot plot for $\%$ DFI vs total fluorescence. This kind of graph allows to interpreting \%DFI data (each dot represents data from one spermatozoon), defining a main population with low $\%$ DFI and a cut-off value for medium and high \%DFI values. In this study, this cut-off value was set at $25 \%$ (vertical line) 


\section{Statistical analysis}

Statistical analyses were carried out using the R statistical environment ( $\mathrm{R}$ Development Core Team, 2007). First, we carried out a general analysis on the effect of treatment on the DNA data. The effect of the treatments was analysed by linear mixed-effects models (male as a random factor). As males seemed to respond differently to some parameters, we also carried out an ANOVA and Tukey test for assessing differences between males within each of the three treatments $(0,6 \mathrm{~h}$ Control and $6 \mathrm{~h}$ Oxidant). The repeatability of each parameter was assessed by using the test described by Bland and Altman (1986), calculating the repeatability coefficient as twice the standard deviation of the differences between the replicates. We used the Wilcoxon signed rank test for checking whether the differences differed significantly from 0 . The discriminating ability of each parameter to distinguish between the Control and Oxidant treatment at $6 \mathrm{~h}$ was estimated by using receiver operating characteristic (ROC) curves (NunezMartinez et al. 2007). The sensitivity (true positive rate) and specificity (true negative rate) of each parameter for

12 different threshold values were calculated by plotting them as an ROC curve. We then calculated the area

13 under curve (AUC) using the integrate method. AUC varies from 0.5 (test with no discriminatory ability) to 1 (perfect discriminatory ability).

\section{Results}

The analysis of data in males showed that bull $\mathrm{C}$ differed significantly from the other two bulls because of lower DNA integrity, both for SCD and SCSA (Fig. 2). Nevertheless, the \%DFI for that bull was still below the values considered problematic for fertility (Evenson 1999). Considering the response to the Oxidant treatment, SCD failed in detecting any difference with the Control (both at 0 and $6 \mathrm{~h}$ ). However, only in bull $\mathrm{C}$ did the SCD show an increase in the percentage of sperma-16 tozoa with halo after incubation at $37^{\circ} \mathrm{C}(\mathrm{p}<0.001)$, both for Control and Oxidant treatments. In this case, the Oxidant treatment yielded a slightly higher percentage of halos than the Control $(\mathrm{p}<0.05)$. Contrarily, $\%$ DFI did not show differences between Control at 0 and Control at $6 \mathrm{~h}$, but increased significantly in the Oxidant treatment for the three bulls (Fig. 2), indicating a decrease in DNA integrity (higher \%DFI). Although this increase was observed in all the three bulls, it was more marked for bull C. SD-DFI increased in the Oxidant treatment too $(\mathrm{p}<0.05)$, but a more detailed analysis indicated that this increase was only significant for bull C. HDS showed a very high dispersion in the $0 \mathrm{~h}$ analysis, being much more homogeneous within and between bulls at $6 \mathrm{~h}$. At that time and only for the Oxidant treatment, the three bulls differed significantly 14 following the pattern $\mathrm{B}<\mathrm{A}<\mathrm{C}$. The results for repeatability and discriminating ability (ROC test) of SCD and SCSA are shown in Table 1. Differences between replicates were small, and not different from 0 $(\mathrm{p}>0.05)$. Repeatability was relatively high for all techniques (low repeatability coefficients). However, $15 \mathrm{SCD}$, being based in subjective microscopy assessment,
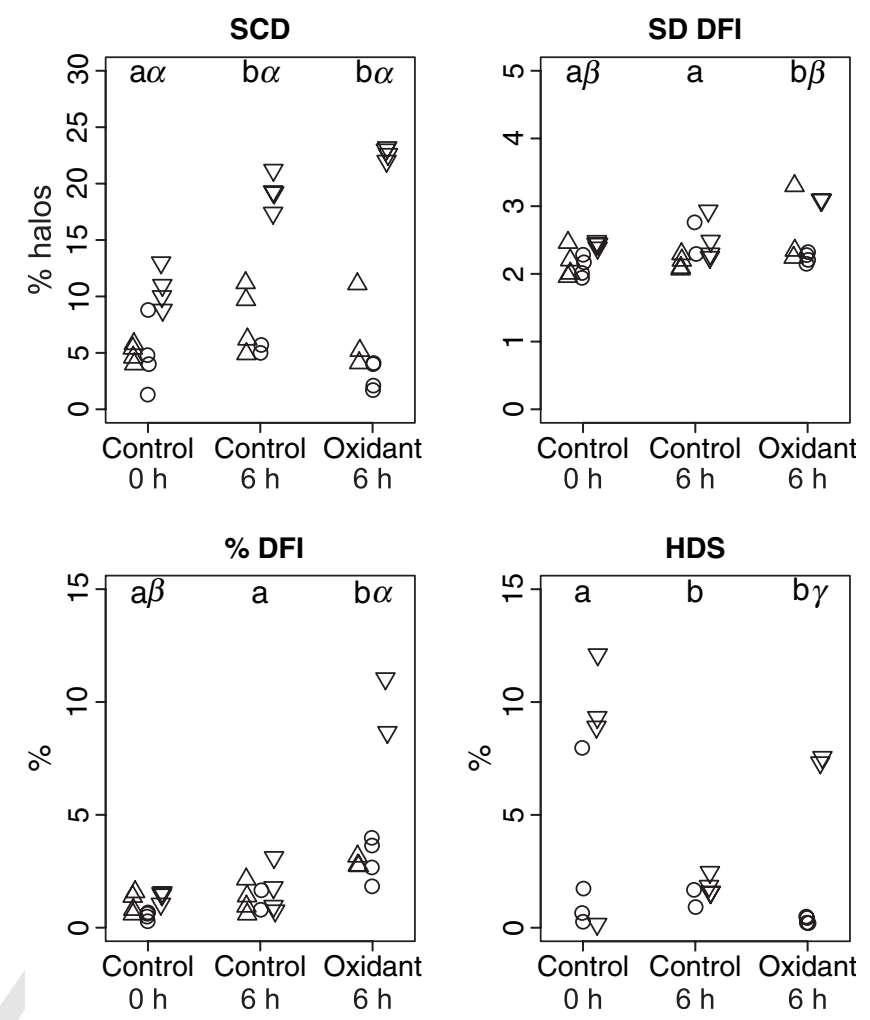

24Fig. 2. Scatter plot showing the distribution of results for each bull and treatment for SCD and SCSA. Bull A: $\triangle$ bull B: $\bigcirc$; bull C: $\nabla$. Lower-case Latin letters indicate significant differences between treatments (Control at $0 \mathrm{~h}$, Control at $6 \mathrm{~h}$ and Oxidant at $6 \mathrm{~h}$ ); lowercase Greek letters indicate significant differences between bulls within each treatment: $\alpha: \mathrm{A} \neq \mathrm{C}, \mathrm{B} \neq \mathrm{C} ; \beta: \mathrm{B} \neq \mathrm{C} ; \gamma: \mathrm{A} \neq \mathrm{B}, \mathrm{A} \neq \mathrm{C}$, $B \neq C$. Notice the different vertical scales used for each parameter

had a lower repeatability. Figure 3 displays a graphical depiction of the test, showing the differences between the repeatability coefficient intervals of SCD and \%DFI for 6SCSA, showing the higher dispersion of the differences for the former. The analysis of the discriminating ability of each parameter, according to the treatment (Control or Oxidant), showed important differences between techniques (Table1 and Fig. 3). The discriminating ability of SCD according to this criteria was almost null (AUC: 0.517 ).In the case of SCSA, \%DFI had an AUC of 0.956 , meaning a very good discriminating ability for this parameter. SD-DFI and HDS showed a low discriminating ability, as expected considering that these parameters only showed differences for bull $\mathrm{C}$ between Control and Oxidant.

\section{Discussion}

The assessment of semen doses from fighting bulls showed that $\%$ DFI results were below $2 \%$ overall. Taking the information published about the SCSA test on bull semen, we would identify all these doses as not having its fertility compromised because of chromatin defects. Indeed, it has been suggested that bull samples with $\%$ DFI $\geq 20 \%$ might have lower fertility (Evenson 1999). Nevertheless, submitting the samples to oxidative stress increased the \%DFI of bull $\mathrm{C}$ to around $10 \%$, 
Table 1. Summary of the results obtained from the repeatability (RPT) and ROC tests. The data shown for RPT are the mean of the differences between replicates, and the repeatability coefficients (2SD of the differences). For the ROC test, data are the area under the curve (AUC) and the optimal cut-off point (OCP) for each curve (the value providing the higher number of true positives and the lower number of false negatives). A higher repeatability coefficient indicates lower repeatability, whereas a higher AUC indicates higher discriminating ability between samples submitted and not submitted to the Oxidant treatment

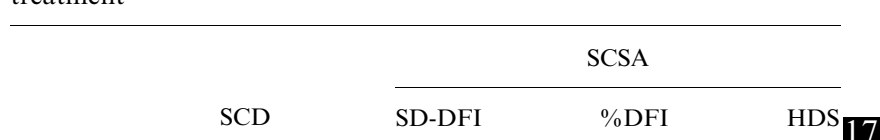

\begin{tabular}{cllll}
\hline RPT & & \%DFI & HDS \\
Mean & 0.306 & 0.004 & 0.138 & 1.384 \\
2SD & 5.9 & 0.648 & 1.764 & 6.389 \\
ROC & & & & \\
AUC & 0.517 & 0.706 & 0.956 & 0.665 \\
OCP & 11.05 & 2.32 & 1.83 & 1.55 \\
\hline
\end{tabular}

while the other two samples still remained below 5\%. The reasons behind that difference merit further study, and highlight the importance of supplementary tests to assess the resistance of semen samples to stressing conditions. At this point, our study must be considered preliminary. Because of how fighting cattle are reared, no fertility data were available. Moreover, the number of cryopreserved doses from fighting bull is still very limited - our germplasm bank being one of the few containing such samples - and only a reduced number of males are represented there. The SCD test did not show any discriminating power for detecting oxidative damage caused by $\mathrm{Fe}^{2+}$ on bull sperm, contrary to the SCSA results. This contrasts with previous studies on this technique on human sperm, which suggested that SCD might be related to DNA damage as measured with DBD-FISH (Fernandez et al. 2003), SCSA (Fernandez et al. 2005b) and other tests (Chohan et al.2006). 17 We have to consider, though, that the SCD test for human sperm $\left(\right.$ Halosperm ${ }^{\circledR}$ ) has a different lysis solution and a different interpretation than the Halomax ${ }^{\circledR}$ produces a halo when the spermatozoa kit for bovine sperm. Halosperm ${ }^{\circledR}$ has intact DNA, whereas Halo$\max ^{\circledR}$ (and the variant for boar sperm) produces a halo 18 when the spermatozoa has damaged DNA. This may difficult the comparison between the human and the bull kits. There is only one previous reference to the Halomax ${ }^{\circledR}$ kit for bull sperm (Garcia-Macias et al. 2006a). In that study, the authors found negative correlations between 90-day non-return rates and both the percentage of halos (SCD) and several SCSA parameters. They also combined the percentage of halos with other sperm parameters and SD-DFI from SCSA
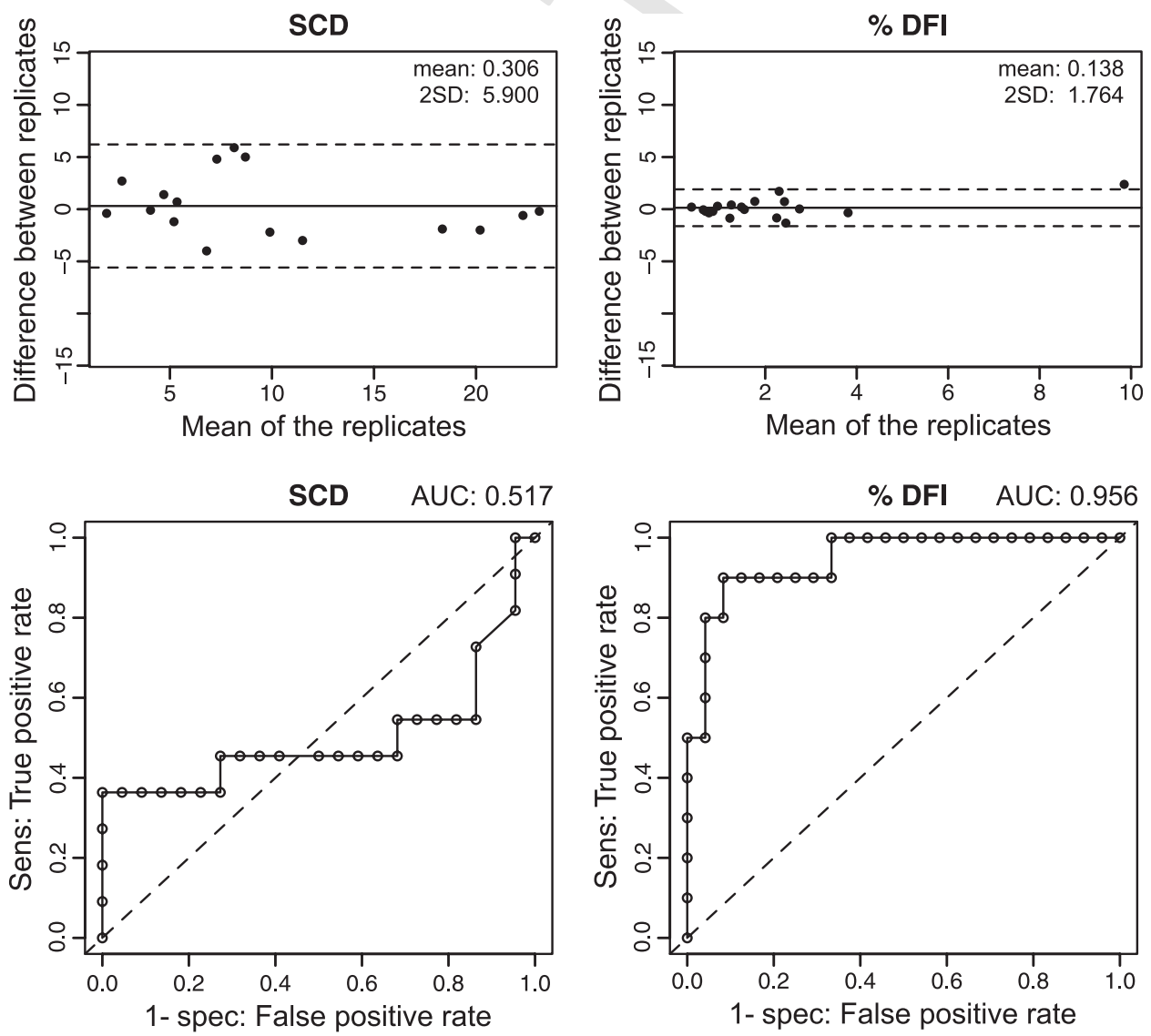

Fig. 3. Bland-Altman plots for repeatability (top) and ROC curves (bottom) for SCD and \%DFI (SCSA). Repeatability plots show the mean of the replicates against their difference (overplotted lines represent the mean of the differences and the coefficient of repeatability, $2 \times \mathrm{SD}$ of the differences). ROC curves ( 1 - specificity vs sensitivity) show the discriminating ability of each test between Control and Oxidant treatments. SCD had low repeatability $(2 \mathrm{SD}=5.9)$ and no predictive ability $(\mathrm{AUC} \sim 0.5)$, whereas $\%$ DFI had better repeatability $(2 \mathrm{SD}=1.764)$ and a very good predictive ability $(\mathrm{AUC} \sim 1)$ 
into a multiple regression formula for predicting the non-return rate, although the predictive value was not high $\left(r^{2}=0.34\right)$. They concluded that SCSA and SCD explained different aspects of sperm DNA damage, both techniques being useful for studying it and even complementary. Unfortunately, these authors did not use other statistical techniques, such as ROC curves or odd ratio calculation, which possibly had improved the comparison between SCSA and SCD for bull sperm. Considering both the results of Garcia-Macias et al. and ours, it seems that at least for the commercial kit SpermBos-Halomax ${ }^{\circledR}$, the SCD render different information that the SCSA. This may be a difference with the Halosperm $^{\circledR}$, for human sperm, which was criticized for not providing additional information than previous tests (Evenson and Wixon 2005a; Schlegel and Paduch 2005). The SCD test might detect some kind of sperm chromatin alterations, which may eventually affect sperm fertility, thus the relations found by GarciaMacias et al. (2006a) and other authors. In our opinion, it is necessary to study the SCD kits for different species, and verify if the information delivered is the same in all cases. In our experiment, the SCD test discriminated bull $\mathrm{C}$ at $0 \mathrm{~h}$ and indicated changes in the sperm of bull $\mathrm{C}$ after the incubation at $37^{\circ} \mathrm{C}$, but apparently not related to the oxidative stress. Thus, it seems that SCD detected a kind of chromatin alteration different to those detected by the SCSA. delaTorre et al.(2007), using SCD on boar sperm, could find increased DNA damage after applying an oxidative stress. However, that stress was much higher $\left(15 \mathrm{~mm} \mathrm{H}_{2} \mathrm{O}_{2}\right.$ for $\left.48 \mathrm{~h}\right)$ than the one used in our study, which might have had introduced artefacts in the analysis. Further research is necessary on this relatively new test to assess its validity on detecting DNA damage and to determine whether the interpretation of the data is the same in different species. Considering the SCSA, \%DFI was the most informative parameter. HDS had a totally different behaviour than the rest of the parameters, as it showed a broad dispersion at $0 \mathrm{~h}$, which disappeared after the incubation period. Evenson and Wixon (2006) proposed that HDS would indicate the proportion of immature sperm in a sample, thus rendering a different kind of information than SD-DFI or \% DFI. In our experiment, the reduction in HDS after $6 \mathrm{~h}$ of incubation may indicate changes during the incubation affecting the organization of sperm chromatin. In fact, other authors have reported changes in the degree of chromatin condensation after incubating spermatozoa in different media (Corcuera et al. 2007).

In conclusion, the SCD test for bull sperm did not discriminate among untreated and oxidized samples and it had a lower repeatability than the SCSA. Nevertheless, it discriminated between bull $\mathrm{C}$ and the others. The SCSA allowed to discriminating between the oxidized and untreated samples and also between bulls. We propose that both tests may be identifying different features of sperm chromatin. In the study of delaTorre 19 et al.(2007), the SCD was performed simultaneously to an analysis of protein loss from the sperm nucleus. Although limited, the results showed a relationship between nuclear protein alteration and DNA damage (formation of halos). In fact, the authors indicated that the lysis solution used in the SCD test alters the chromatin in a different manner than the acid-detergent used in SCSA, causing a disintegration of the protein scaffold, which may explain the differences between both techniques. The SCD is a potentially useful technique but it must be further studied. The higher subjectivity of this technique is a major drawback, which might be overcome with the development of automated systems for detecting halo sizes. Nevertheless, the lack of responsiveness discriminating among control or oxidized samples raises questions on the interpretation of this test, which must be solved before approaching the extensive use of this test.

\section{Acknowledgements}

This study was supported by the Spanish Ministry of Education and Science (AGL2004-05904GAN) and by the Council for Education and Science of Junta de Castilla-La Mancha (PAC-06-047). Felipe Martínez-Pastor was supported by the 'Juandela Cierva' program (Spanish Ministry of Education and Science).

\section{References}

Agarwal A, Allamaneni SSR, 2005: Sperm DNA damage assessment: a test whose time has come. Fertil Steril 84, 850853.

Agarwal A, Said TM, 2003: Role of sperm chromatin abnormalities and DNA damage in male infertility. Hum Reprod Update 9, 331-345.

Álvarez M, García-Macías V, Boixo J, Martínez-Pastor F, Muro J, Bernardo J, Alves S, Anel E, Anel L, 2006: Effect of two anesthetic protocols in blood cortisol levels of electroejaculated bulls. Reprod Domest Anim 41, 118, 8th International Congress of the Spanish Association of Animal

Reproduction, La Manga del Mar Menor, Spain.

Ballachey BE, Hohenboken WD, Evenson DP, 1987: Heterogeneity of sperm nuclear chromatin structure and its relationship to bull fertility. Biol Reprod 36, 915-925.

Blackburn HD, 2004: Development of national animal genetic resource programs. Reprod Fertil Dev 16, 27-32.

Bland JM, Altman DG, 1986: Statistical methods for assessing agreement between two methods of clinical measurement. Lancet 1, 307-310.

Bochenek M, Smorag Z, Pilch J, 2001: Sperm chromatin structure assay of bulls qualified for artificial insemination. Theriogenology 56, 557-567.

Bungum M, Humaidan P, Axmon A, Spano M, Bungum L, Erenpreiss J, Giwercman A, 2007: Sperm DNA integrity assessment in prediction of assisted reproduction technology outcome. Hum Reprod 22, 174-179.

Chen CS, Chao HT, Pan RL, Wei YH, 1997: Hydroxyl radical-induced decline in motility and increase in lipid peroxidation and DNA modification in human sperm. Biochem Mol Biol Int 43, 291-303.

Chohan KR, Griffin JT, Lafromboise M, Jonge CJD, Carrell DT, 2006: Comparison of chromatin assays for DNA fragmentation evaluation in human sperm. J Androl 27, 53-59.

Corcuera BD, Marigorta P, Sagues A, Saiz-Cidoncha F, PerezGutierrez JF, 2007: Effect of lactose and glycerol on the motility, normal apical ridge, chromatin condensation and chromatin stability of frozen boar spermatozoa. Theriogenology 67, 1150-1157.

De Ambrogi M, Ballester J, Saravia F, Caballero I, Johannisson A, Wallgren M, Andersson M, Rodriguez-Martinez H, 2006: Effect of storage in short- and long-term commercial 
semen extenders on the motility, plasma membrane and chromatin integrity of boar spermatozoa. Int J Androl 29, 543-552.

Dias GM, Retamal CA, Tobella L, Arnholdt ACV, Lopez ML, 2006: Nuclear status of immature and mature stallion spermatozoa. Theriogenology 66, 354-365.

Enciso M, Muriel L, Fernandez JL, Goyanes V, Segrelles E, Marcos M, Montejo JM, Ardoy M, Pacheco A, Gosalvez J, 2006: Infertile men with varicocele show a high relative proportion of sperm cells with intense nuclear damage level, evidenced by the sperm chromatin dispersion test. J Androl 27, 106-111.

Erenpreiss J, Spano M, Erenpreisa J, Bungum M, Giwercman A, 2006: Sperm chromatin structure and male fertility: biological and clinical aspects. Asian J Androl 8, 11-29.

Evenson DP, 1999: Loss of livestock breeding efficiency due to uncompensable sperm nuclear defects. Reprod Fertil Dev 11, 1-15.

Evenson DP, Wixon R, 2005a: Comparison of the halo sperm test kit with the sperm chromatin structure assay (SCSA) infertility test in relation to patient diagnosis and prognosis. Fertil Steril 84, 846-849.

Evenson DP, Wixon R, 2005b: Environmental toxicants cause sperm DNA fragmentation as detected by the sperm chromatin structure assay (SCSA(R)). Toxicol Appl Pharmacol 207, 532-537.

Evenson DP, Wixon R, 2006: Clinical aspects of sperm DNA fragmentation detection and male infertility. Theriogenology 65, 979-991.

Evenson DP, Larson KL, Jost LK, 2002: Sperm chromatin structure assay: its clinical use for detecting sperm DNA fragmentation in male infertility and comparisons with other techniques. J Androl 23, 25-43.

Fernandez J, Muriel L, Rivero M, Goyanes V, Vazquez R, Alvarez J, 2003: The sperm chromatin dispersion test: a simple method for the determination of sperm DNA fragmentation. J Androl 24, 59-66.

Fernandez JL, Muriel L, Goyanes V, Segrelles E, Gosalvez J, Enciso M, LaFromboise M, Jonge CD, 2005a: Halosperm is an easy, available, and cost-effective alternative for determining sperm DNA fragmentation. Fertil Steril 84, 860.

Fernandez JL, Muriel L, Goyanes V, Segrelles E, Gosalvez J, Enciso M, LaFromboise M, Jonge CD, 2005b: Simple determination of human sperm DNA fragmentation with an improved sperm chromatin dispersion test. Fertil Steril 84, 833-842.

Fernandez-Santos MR, Martinez-Pastor F, Garcia-Macias V, Esteso MC, Soler AJ, Paz P, Anel L, Garde JJ, 2007: Sperm characteristics and DNA integrity of Iberian red deer (Cervus elaphus hispanicus) epididymal spermatozoa frozen in the presence of enzymatic and nonenzymatic antioxidants. J Androl 28, 294-305.

Garcia-Macias V, dePaz P, Martinez-Pastor F, Alvarez M, Gomes-Alves S, Bernardo J, Anel E, Anel L, 2006a: DNA fragmentation assessment by flow cytometry and SpermBos-Halomax (bright-field microscopy and fluorescence

21 microscopy) in bull sperm. Int J Androl ??, ???-???

Garcia-Macias V, Martinez-Pastor F, Alvarez M, Borragan S, Chamorro CA, Soler AJ, Anel L, dePaz P, 2006b: Seasonal changes in sperm chromatin condensation in ram (Ovis aries), Iberian red deer (Cervus elaphus hispanicus), and brown bear (Ursus arctos). J Androl 27, 837-846.

Garcia-Macias V, Martinez-Pastor F, Alvarez M, Garde JJ, Anel E, Anel L, dePaz P, 2006c: Assessment of chromatin status (SCSA) in epididymal and ejaculated sperm in Iberian red deer, ram and domestic dog. Theriogenology 66, 19211930.

Garde JJ, Soler AJ, Cassinello J, Crespo C, Malo AF, Espeso G, Gomendio M, Roldan ERS, 2003: Sperm cryopreserva- tion in three species of endangered gazelles (Gazella cuvieri, G. dama mhorr, and G. dorcas neglecta). Biol Reprod 69, 602-611.

Hernandez M, Roca J, Ballester J, Vazquez JM, Martinez EA, Johannisson A, Saravia F, Rodriguez-Martinez H, 2006: Differences in SCSA outcome among boars with different sperm freezability. Int J Androl 29, 583-591.

Howard JG, Pursel VG, Wildt DE, Bush M, 1981: Comparison of various extenders for freeze-preservation of semen from selective captive wild ungulates. J Am Vet Med Assoc 179, 1157-1161.

Januskauskas A, Johannisson A, Rodriguez-Martinez H, 2003: Subtle membrane changes in cryopreserved bull semen in relation with sperm viability, chromatin structure, and field fertility. Theriogenology 60, 743-758.

Kasimanickam R, Nebel RL, Peeler ID, Silvia WL, Wolf KT, McAllister AJ, Cassell BG, 2006a: Breed differences in competitive indices of Holstein and Jersey bulls and their association with sperm DNA fragmentation index and plasma membrane integrity. Theriogenology 66, 13071315 .

Kasimanickam R, Pelzer KD, Kasimanickam V, Swecker WS, Thatcher CD, 2006b: Association of classical semen parameters, sperm DNA fragmentation index, lipid peroxidation and antioxidant enzymatic activity of semen in ram-lambs. Theriogenology 65, 1407-1421.

Lloyd DR, Phillips DH, 1999: Oxidative DNA damage mediated by copper(II), iron(II) and nickel(II) Fenton reactions: evidence for site-specific mechanisms in the formation of double-strand breaks, 8-hydroxydeoxyguanosine and putative intrastrand cross-links. Mutat Res 424, 23-36.

Lo CC, Thompson JA, Lowry VK, Varner DD, 2002: Effect of storage time and temperature on stallion sperm DNA and fertility. Theriogenology 57, 1135-1142.

Love CC, 2005: The sperm chromatin structure assay: a review of clinical applications. Anim Reprod Sci 89, 39-45.

Martinez-Pastor F, Johannisson A, Gil J, Kaabi M, Anel L, Paz P, Rodriguez-Martinez H, 2004: Use of chromatin stability assay, mitochondrial stain $\mathrm{JC}-1$, and fluorometric assessment of plasma membrane to evaluate frozen-thawed ram semen. Anim Reprod Sci 84, 121-133.

Muriel L, Garrido N, Fernandez JL, Remohi J, Pellicer A, delos Santos MJ, Meseguer M, 2006a: Value of the sperm deoxyribonucleic acid fragmentation level, as measured by the sperm chromatin dispersion test, in the outcome of in vitro fertilization and intracytoplasmic sperm injection. Fertil Steril 85, 371-383.

Muriel L, Meseguer M, Fernandez JL, Alvarez J, Remohi J, Pellicer A, Garrido N, 2006b: Value of the sperm chromatin dispersion test in predicting pregnancy outcome in intrauterine insemination: a blind prospective study. Hum Reprod 21, 738-744.

Muriel L, Goyanes V, Segrelles E, Gosalvez J, Alvarez JG, Fernandez JL, 2007: Increased aneuploidy rate in sperm with fragmented DNA as determined by the sperm chromatin dispersion (SCD) test and FISH analysis. J Androl 28, 38-49.

Nunez-Martinez I, Moran JM, Pena FJ, 2005: Do computerassisted, morphometric-derived sperm characteristics reflect DNA status in canine spermatozoa? Reprod Domest Anim 40, 537-543.

Nunez-Martinez I, Moran JM, Pena FJ, 2007: Sperm indexes obtained using computer-assisted morphometry provide a forecast of the freezability of canine sperm. Int J Androl 30, $182-189$.

Ostermeier GC, Sargeant GA, Yandell BS, Evenson DP, Parrish JJ, 2001: Relationship of bull fertility to sperm nuclear shape. J Androl 22, 595-603. 
Perez-Llano B, Enciso M, Garcia-Casado P, Sala R, Gosalvez J, 2006: Sperm DNA fragmentation in boars is delayed or abolished by using sperm extenders. Theriogenology $\mathbf{6 6}$, 2137-2143.

R Development Core Team, 2007: R: A Language and 22 Environment for Statistical Computing. R Foundation for Statistical Computing, Vienna, Austria.

Roth TL, Weiss RB, Buff JL, Bush LM, Wildt DE, Bush M, 1998: Heterologous in vitro fertilization and sperm capacitation in an endangered African antelope, the scimitarhorned oryx (Oryx dammah). Biol Reprod 58, 475-482.

Saacke RG, Dalton JC, Nadir S, Nebel RL, Bame JH, 2000: Relationship of seminal traits and insemination time to fertilization rate and embryo quality. Anim Reprod Sci 6061, 663-677.

Schlegel PN, Paduch DA, 2005: Yet another test of sperm chromatin structure. Fertil Steril 84, 854-859.
delaTorre J, Lopez-Fernandez C, Pita M, Fernandez J, Johnston S, Gosalvez J, 2007: Simultaneous observation of DNA fragmentation and protein loss in the boar spermatozoon following application of the Sperm Chromatin 2 Dispersion test (SCDt). J Androl ???, ???.

Waterhouse KE, Haugan T, Kommisrud E, Tverdal A, Flatberg G, Farstad W, Evenson DP, De Angelis PM, 2006: Sperm DNA damage is related to field fertility of semen from young Norwegian Redbulls. Reprod Fertil Dev 18, 781-788.

\section{Submitted: 21 Jan 2008}

Author's address (for correspondence): F Martínez-Pastor, Grupo de Biología de la Reproducción, IREC, ETSIA, Campus Universitario s/n,02071 Albacete, Spain. E-mail: felipe.martínez@uclm.es 


\section{Author Query Form}

Journal: RDA

Article: $\quad 1098$

Dear Author,

During the copy-editing of your paper, the following queries arose. Please respond to these by marking up your proofs with the necessary changes/additions. Please write your answers on the query sheet if there is insufficient space on the page proofs. Please write clearly and follow the conventions shown on the attached corrections sheet. If returning the proof by fax do not write too close to the paper's edge. Please remember that illegible mark-ups may delay publication.

Many thanks for your assistance.

\begin{tabular}{|c|c|c|}
\hline $\begin{array}{l}\text { Query } \\
\text { reference }\end{array}$ & Query & Remarks \\
\hline Q1 & $\begin{array}{l}\text { Author: Fighting Bull (10 occurrences in the text)-please check } \\
\text { terminology. }\end{array}$ & \\
\hline Q2 & Author: huge choice—or vast array? & \\
\hline Q3 & Author: please define IVF and ICSI. & \\
\hline Q4 & Author: being sensible to establish—please reword. & \\
\hline Q5 & $\begin{array}{l}\text { Author: before testing fertility or seminal characteristics-please check } \\
\text { amendment. }\end{array}$ & \\
\hline Q6 & Author: positive treatment-please reword. & \\
\hline Q7 & Author: 100 those untreated-please check sense. & \\
\hline Q8 & Author: please provide city for Bayer and Braun. & \\
\hline Q9 & Author: is based in-please reword. & \\
\hline Q10 & $\begin{array}{l}\text { Author: please provide manufacturer information for Becton Dickinson: } \\
\text { town, state (if USA) and country. }\end{array}$ & \\
\hline Q11 & $\begin{array}{l}\text { Author: please provide manufacturer information for CellQuestv. } 3 \text { software: } \\
\text { company name, town, state (if USA) and country. }\end{array}$ & \\
\hline Q12 & Author: were calculated by plotting them-please check amendment. & \\
\hline Q13 & Author: integrate method-or 'integrated' method? & \\
\hline Q14 & Author: following the pattern-is the inclusion of the pattern $\mathrm{OK}$ ? & \\
\hline Q15 & Author: based in-please reword. & \\
\hline Q16 & Author: the higher dispersion of the differences-please reword. & \\
\hline Q17 & Author: We have to consider-please check sentence for sense. & \\
\hline Q18 & Author: This may difficult-please check sense of difficult. & \\
\hline Q19 & Author: to an analysis — did you mean for an analysis? & \\
\hline Q20 & $\begin{array}{l}\text { Author: 8th International Congress of the Spanish Association of Animal } \\
\text { Reproduction, La Manga del Mar Menor, Spain-should this information be } \\
\text { retained? }\end{array}$ & \\
\hline
\end{tabular}




\begin{tabular}{|l|l|l|}
\hline Q21 & Author: please provide volume number and page span. & \\
\hline Q22 & Author: please provide volume number and page span. & \\
\hline Q23 & Author: Latin-please check text. & \\
\hline Q24 & $\begin{array}{l}\text { Au: Kindly check the capital letters A, B \& C in this caption, which are not } \\
\text { mentioned in the figure. }\end{array}$ & \\
\hline
\end{tabular}




\section{Please correct and return this set}

Please use the proof correction marks shown below for all alterations and corrections. If you wish to return your proof by fax you should ensure that all amendments are written clearly in dark ink and are made well within the page margins.

\begin{tabular}{|c|c|c|}
\hline Instruction to printer & Textual mark & Marginal mark \\
\hline Leave unchanged & ... under matter to remain & ( \\
\hline $\begin{array}{l}\text { Insert in text the matter } \\
\text { indicated in the margin }\end{array}$ & $h$ & $\begin{array}{l}\text { New matter followed by } \\
h \text { or } h \otimes\end{array}$ \\
\hline Delete & $\begin{array}{l}\text { I through single character, rule or underline } \\
\text { or }\end{array}$ & $\sigma$ or $\sigma / \otimes$ \\
\hline $\begin{array}{l}\text { Substitute character or } \\
\text { substitute part of one or } \\
\text { more word(s) }\end{array}$ & / through letter or & $\begin{array}{l}\text { new character / or } \\
\text { new characters / }\end{array}$ \\
\hline Change to italics & — under matter to be changed & $\leftarrow$ \\
\hline Change to capitals & $\equiv$ under matter to be changed & $\equiv$ \\
\hline Change to small capitals & $=$ under matter to be changed & $=$ \\
\hline Change to bold type & $\sim$ under matter to be changed & $\sim$ \\
\hline Change to bold italic & $\approx$ under matter to be changed & $\underline{s i n}$ \\
\hline Change to lower case & Encircle matter to be changed & $\not$ \\
\hline Change italic to upright type & (As above) & \\
\hline Change bold to non-bold type & (As above) & \\
\hline Insert 'superior' character & $\begin{array}{l}\text { I through character or } \\
K \text { where required }\end{array}$ & $\begin{array}{l}y^{\prime} \text { or } y \\
\text { under character } \\
\text { e.g. } y^{2} \text { or } y^{2}\end{array}$ \\
\hline Insert 'inferior' character & (As above) & $\begin{array}{l}\text { L } \\
\text { over character } \\
\text { e.g. } \hat{\imath}\end{array}$ \\
\hline Insert full stop & (As above) & $\odot$ \\
\hline Insert comma & (As above) & , \\
\hline Insert single quotation marks & (As above) & $\begin{array}{l}\dot{y} \text { or } \dot{X} \text { and/or } \\
\dot{y} \text { or } \dot{X}\end{array}$ \\
\hline Insert double quotation marks & (As above) & $\begin{array}{l}\ddot{y} \text { or } \ddot{y} \text { and/or } \\
\ddot{y} \text { or } \ddot{x}\end{array}$ \\
\hline Insert hyphen & (As above) & $1-1$ \\
\hline Start new paragraph & $\digamma$ & 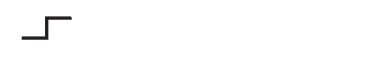 \\
\hline No new paragraph & $\infty$ & $\omega$ \\
\hline Transpose & $\sqcup$ & ᄃ \\
\hline Close up & linking $\bigcirc$ characters & \\
\hline $\begin{array}{l}\text { Insert or substitute space } \\
\text { between characters or words }\end{array}$ & $\begin{array}{l}\text { I through character or } \\
\Lambda \text { where required }\end{array}$ & \\
\hline $\begin{array}{l}\text { Reduce space between } \\
\text { characters or words }\end{array}$ & $\begin{array}{l}\text { between characters or } \\
\text { words affected }\end{array}$ & $\uparrow$ \\
\hline
\end{tabular}

